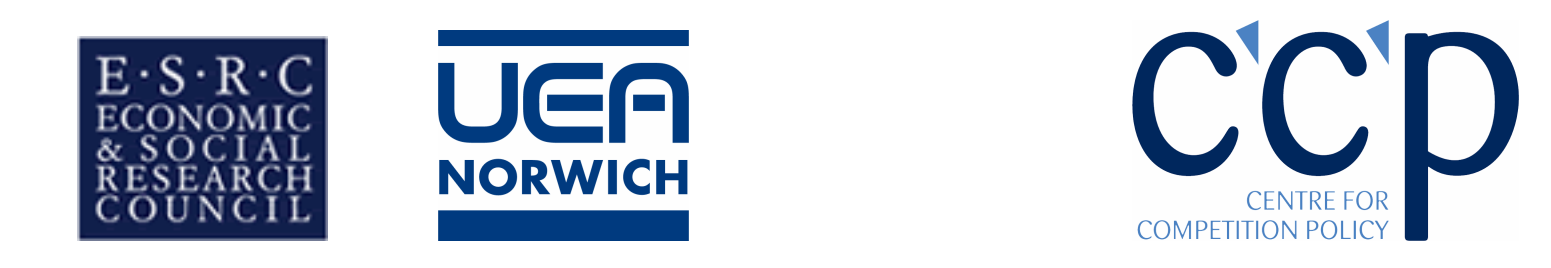

\title{
Competition Law Enforcement: the "Free-Riding" Plaintiff and Incentives for the Revelation of Private Information
}

\author{
by \\ Michael Harker and Morten Hviid \\ ESRC Centre for Competition Policy and Norwich Law School, \\ University of East Anglia
}

\section{CCP Working Paper 06-9}

\begin{abstract}
The past and current reluctance of firms and individuals to use private enforcement suggests that there are limited incentives for self-help. The key contribution of private enforcement to overall deterrence derives from cases which would not otherwise be brought, not simply because of resource constraints, but also because relevant information would not otherwise have come to light. In terms of revealing such private information, cases initiated and pursued by private litigants add much more to the equation than do cases merely following-on from decisions made by competition authorities. In this paper we use a simple model to highlight what features of the private enforcement system promote and hamper the use of these two different types of private enforcement. A key finding is that that to encourage new cases, it is essential that private enforcement is quicker than the time it takes to get a decision in a follow-on case.
\end{abstract}

April 2006

JEL Classification: K21; K13; K41

Keywords: Private Enforcement; Litigation; Deterrence; Competition Law

\section{Acknowledgements:}

The support of the Economic and Social Research Council (UK) is gratefully acknowledged. Part of the work was carried out while the second author was visiting UC Berkeley and he would like to express his thanks for their hospitality. We would like to thank Pinar Akman and Andreas Stephan for helpful comments. Part of this work was presented at the $7^{\text {th }}$ Clasf conference and we thank participants for their helpful comments and remarks. The usual disclaimer applies.

\section{Contact details:}

m.harker@uea.ac.uk \& m.hviid@uea.ac.uk, ESRC Centre for Competition Policy, University of East Anglia, Norwich, NR4 7TJ, UK. www.ccp.uea.ac.uk t: +44 (0) 1603593715 f: + 44(0) 1603591622

ISSN 1745-9648 


\section{Introduction}

The increased use of private enforcement brings with it a number of potential benefits. Principal among these is the possibility of increasing the incentives for the revelation of private information, the main subject of this paper. If competition litigation by firms is to augment the overall resources for the enforcement of competition law, then the following conditions must be met: the action brought by the firm in question (the plaintiff) obviates the need for an intervention by the public enforcement agency (whether this is socially desirable depends upon the relative efficiencies of the enforcement mechanisms); and, the prospect of damages provides the plaintiff with incentives to reveal private information which would not otherwise have come to light.

It can be said that the information asymmetries between two firms who operate in the same or related markets are smaller than those which exist between a competition authority and the firms. Arguably the main benefit of private enforcement is that it brings into the open information about violations which competition authorities were not aware of, nor possibly able to detect.

Not all types of private cases are likely to lead to the same degree of revelation of crucial and valuable information. Following Kauper and Snyder (1985), we divide private litigation cases into two categories, in the following referred to as de novo and follow-on. ${ }^{1}$ With a de novo case, a plaintiff initiates a private action based on an alleged breach of competition law. The plaintiff must provide the necessary evidence to secure an infringement decision and faces the risk of having to pay at least its own costs, and possibly the costs of the defendant, should it lose. The evidence provided is directly tested in court and the plaintiff has a strong incentive to reveal all information it has which may lead to an infringement decision. In a follow-on case, the would-be plaintiff waits for the decision of the competition authority and only initiates a case where the infringement has been established. ${ }^{2}$ Follow-on cases are generally less expensive for the plaintiff, but how great the savings are depends on the jurisdictions. These differ on whether or not the decision of the competition authority can

\footnotetext{
${ }^{1}$ We abstract from a discussion of where competition law is being used as a shield as in, for example, an IP infringement case where the defendant offers a defence based on Article 82. Of course in such cases the defendant has no choice over proceedings.

${ }^{2}$ In the US, follow-on cases typically start well before the competition authority has reached its decision. The reason for this can be found in the incentive provided by class actions. Being the first law firm to bring a suit puts the firm is a strong position to be in charge of the class action. Thus there may be a race between law firms to initiate the case as soon as possible. In a EU context where class actions are not generally available, we would expect the competition authority to have scrutinised the case and reached a decision before any potential followon case by the plaintiff is initiated against the defendant.
} 
be used as conclusive evidence of a violation, leaving the plaintiff with the task merely of establishing causality and the level of damages. Follow-on cases can also increase the potential for the revelation of private information, giving a would-be plaintiff an incentive to alert the competition authority to a violation. The value of this information is, however, tempered by the need on the part of the competition authority to exercise closer scrutiny to it given the potential vested interest of a complainant who is also a potential plaintiff. A future plaintiff may have an incentive to provide partial or incomplete information to the competition authority. Thus not only may more information be revealed through de novo cases, but this information may be of higher "quality".

Both de novo and follow-on cases can be vehicles for the revelation of private information and may, therefore, lead to more infringement findings. However, de novo cases have far more merit insofar as they represent an augmentation of resources for the enforcement of competition law which, providing there are appropriate safeguards in place, may be expected to lead to a higher level of deterrence against anticompetitive behaviour. A follow-on case, on the other hand, involves free-riding ${ }^{3}$ on public resources which has rather colourfully been referred to as a case where "plaintiffs' counsel can be cast as jackals to the government's lion, arriving on the scene after some enforcement or administrative agency has made the kill". There are other reasons besides for encouraging private plaintiffs to pursue de novo rather than follow-on cases, and these are discussed further in section 2.

Given the relative benefits to society of de novo over follow-on cases, it is important to understand how to optimise an enforcement system (comprising of both public and private elements) so that plaintiffs with access to sufficient information to secure an infringement finding do so without relying upon public resources. In section 3, we provide a simple model to understand the relative incentives of a would-be plaintiff to bring either type of case. We show that, for de novo cases to be more attractive to would-be plaintiffs than follow-on cases, the former should be relatively quick and not too costly. If this is not so, the case filtering and evidence produced by the competition authority will mean that plaintiffs are better off trying to persuade the competition authority to investigate with a view to pursuing a follow-on action. Given the low incidence of private enforcement in EU member states, this has clearly

\footnotetext{
${ }^{3}$ This free riding refers to the individual not bearing all the costs of the action it is taking for private gain. Where private enforcement leads to deterrence of even clarification of the law, we can identify another form of free-riding, that of the individual plaintiff by society.

${ }^{4}$ In re Gulf Oil/Cities Service Tender Offer Litigation, 142 F.R.D. 588 (S.D.N.Y.1992), though used to indicate the absence of free-riding in that case.
} 
been the dominant strategy for aggrieved firms hitherto. Section four of the paper discusses policy implications and section 5 discusses the main findings and concludes.

\section{De novo vs. follow-on cases}

The potential benefits to the plaintiff of a de novo case over a follow-on case are twofold. First, the case may be resolved faster. Typically it can be more tightly defined than a case brought by a competition authority. ${ }^{5}$ Furthermore, in the cases we envisage, the plaintiff already has in its possession relevant information from which, possibly with additional information obtained through discovery, it can construct the evidence necessary to pursue a realistic infringement case through the court. Speed may well be of the essence to an aggrieved firm, for example, if the competition law issue involves predatory pricing, a timely resolution may ensure that the plaintiff does not exit the market. ${ }^{6}$ Secondly, the defendant in a private case may be willing to settle, shortening the length and costs of the case. While competition authorities often have the power to agree a settlement, even cartel cases where those accused have admitted an infringement in return for leniency, the duration of these cases does not appear to be shortened dramatically. ${ }^{7}$ From the above discussion, it is clear that de novo cases can provide benefits to society by providing a more efficient enforcement mechanism (in terms of costs and time).

There are, however, a number of reasons why a plaintiff may prefer to pursue a follow-on case instead, free-riding on the resources of the competition authority. One of the relative benefits of a follow-on case is that the courts may be more prepared to listen to economic arguments put forward by a competition authority than a private litigant, so that the probability of a violation being established is higher. Secondly, because of its expertise in competition analysis, the competition authority is typically less likely to make errors in its

\footnotetext{
${ }^{5}$ We think this a reasonable assumption in most cases given that a de novo case will typically involve the resolution of a bilateral dispute between two firms, whereas a case before the competition authority may involve wider parties. More generally, a competition authority is likely to look at a broader range of issues or markets than would a private litigant.

${ }^{6}$ It should be noted, however, that under Regulation 1/2003 both the Commission and national competition authorities have power to impose interim remedies (Articles 8 and 5 respectively).

${ }^{7}$ See e.g. Bremmer (2005), who looked at the effect of a lenience program on the length of a competition authority investigation. He concludes (p.34): "Information revelation may be accompanied by a reduction of investigation and prosecution cost which we proxy by the duration of the investigation. Surprisingly, there is no statistically significant relationship between investigation duration and cooperation, although the average duration of an investigation decreased after adopting the leniency program. Perhaps, this is attributable to the fact that while investigation is facilitated by induced self-reporting, prosecution becomes more expansive as the assessment of penalties gets more time-consuming."
} 
decision, ${ }^{8}$ leading to greater predictability and hence higher expected settlements. Thirdly, the competition authority may have more powerful means to obtain information, for example, powers to conduct dawn raids and cooperative agreements with other enforcement agencies. Finally, the cost to the plaintiff is much lower when a large part of the evidence has been gathered and presented by the competition authority. ${ }^{9}$ Similarly the costs of the defendant in the private action may be smaller with a follow-on case. ${ }^{10}$ While this may imply that less rent can be squeezed from the defendant in settlement, see Wagener (2003), ${ }^{11}$ this reduction in costs is important at least in the UK setting. In the UK, as in most other EU member states, the loser pays all case related costs and while there is little or no chance of losing a follow-on case, there is always some probability that the plaintiff will lose a de novo case. ${ }^{12}$

From an optimal enforcement point of view, while both de novo and follow-on cases offer incentives to reveal private information, the former cases are likely to yield more valuable information. Moreover, follow-on cases, represent a form of free-riding by the individual plaintiff on the resources of the competition authority. How might a plaintiff be persuaded to pursue de novo case instead, sparing the resources of the competition authority to pursue other (perhaps more urgent) cases?

\section{The Incentives to initiate a de novo case}

The aim of this section is to provide a simple model to highlight the incentives of a plaintiff to bring respectively a de novo and a follow-on case. The results from the model will

\footnotetext{
${ }^{8}$ Thus Stephenson (2005, p. 116) "without the involvement of an expert government agency in the course of litigation, the risk of erroneous decisions in private actions may increase, as courts must decide difficult issues without the benefit of an administrative record or the agency's expert opinion." There are some cases, such as restrictive practices cases, which are close enough to contract cases that the court will feel comfortable to proceed without specialist knowledge and without increasing the risk of errors . In other cases, arguments are so complex and subject specific that a more specialist court such as the UK Competition Appeal Ttibunal appears a better choice and where one would expect follow-on cases to lead to strictly fewer errors.

${ }^{9}$ See also the discussion in Rodger and MacCulloch (1998, p. 588) on the value of public information for private litigants.

${ }^{10}$ Of course, the would-be defendant will incur costs in defending an infringement decision by a competition authority. These are, however, costs which the defendant will incur irrespective of whether or not a follow-on case ensues and are because they are not recoverable are not relevant to it when it is considers how much to offer in settlement.

${ }^{11}$ Wagener show how the US system of one-sided fee shifting in antitrust cases, whereby if the plaintiff wins the loser pay all costs but if the defendant wins, each pay own costs, create incentives for frivolous suits aimed solely at rent extraction. In particular he shows that the plaintiff has a disproportionate incentive to increase its trial costs, making the defendant willing to offer more to settle the case before these costs are accrued.

12 While there is some possibility of using a no-win-no-fee agreement with the legal team, note that this payment method is not well suited to the English cost allocation system of loser pays. The way this has commonly been addressed in the UK is for the plaintiff to take out insurance, however in cases which can run into millions of pounds, this does not seem an attractive option for many.
} 
assist us in considering issues of mechanism design having regard in particular to the nexus between public and private enforcement routes.

The scenario we are considering is one in which a potential plaintiff has obtained some information which points to a violation of competition law by which it has been harmed. ${ }^{13}$ To highlight the importance of private litigation to reveal private information held by the plaintiff, we assume that if the potential plaintiff does not act upon this information, nothing will happen. If the potential plaintiff decides to use the information, it can do so in two different ways. It can use it as the starting point for a de novo case, where the plaintiff would provide the necessary resources to investigate the case. Alternatively, the potential plaintiff could pass (some of) the information to the competition authority in the hope that they would take up the case and provide the resources for a full investigation. Depending on the outcome of this investigation, the plaintiff could then initiate a follow-on case. In choosing between these alternative courses of action, we will assume that the plaintiff will select the one which yields the greatest possible expected monetary benefits. ${ }^{14}$

We will use the following notation. Let $\delta$ be the per-period discount factor, $0<\delta \leq 1$, where values close to 1 indicate a high level of patience. Thus one pound t periods from now is worth $\delta^{t}$ today. ${ }^{15}$ For simplicity we assumed the discount factor to be the same for both plaintiff and defendant. Let subscript $\mathrm{N}$ denote a de novo case while subscript $\mathrm{F}$ denotes a follow-on case. Let $t_{\mathrm{i}}$ be the time the case takes until there is a final decision for the plaintiff. Thus for the follow-on case, this includes both the time taken by the initial case of the competition authority, $\mathrm{t}_{\mathrm{F}}^{\mathrm{CA}}$, and the time taken by the subsequent private case, $\mathrm{t}_{\mathrm{F}}^{\mathrm{FO}}$. With this notation, the total length of the follow-on case is $\mathrm{t}_{\mathrm{F}}=\mathrm{t}_{\mathrm{F}}^{\mathrm{CA}}+\mathrm{t}_{\mathrm{F}}^{\mathrm{FO}}$. Let $\mathrm{p}_{\mathrm{N}}$ be the probability assessed at the time of initiating the de novo case of the court finding in favour of the plaintiff. In the follow-on case, we assume that a finding of an infringement by the competition authority is conclusive evidence of a violation in the private follow-on case, while a non-

\footnotetext{
${ }^{13}$ Thus we explicitly exclude follow-on cases where future plaintiffs only learn about the infringement during or after the compeitition authority's case. Such future plaintiffs do not add to the number of cases pursued.

${ }^{14}$ This amounts to assuming that the plaintiff is risk neutral. A risk averse plaintiff, faced with two possible lotteries, such as a court case or a settlement, each having the same expected returns, would prefer the one with less variability. Since the de novo case is more risky because the probability of losing and hence having to pay the defendants costs are higher than a follow on case, this assumption biases any decision between the two cases in favour of the de novo cases. The consequence of this is discussed further in the conclusion.

${ }^{15}$ The discount factor may be close to 1 because interest rates are very low and hence money keep their value. However, we can also interpret the discount factor as a way to capture whether or not the award includes pretrial interest. If not, the discount factor would all else being equal be smaller as getting the award later is less valuable in present value terms.
} 
infringement decision bars a follow-on case. Given this, the probability of the plaintiff carrying the day in a follow-on case, assessed at the date where the plaintiff pass the information on to the competition authority, $\mathrm{p}_{\mathrm{F}}$ is the probability that the latter finds a violation. ${ }^{16}$ Let $\mathrm{D}_{\mathrm{i}}$ be the damages awarded to the plaintiff by the court. Finally, let $C_{i}^{P}$ and $C_{i}^{D}$ be the costs of the plaintiff and defendant of a private case and let total costs be $C_{i} \equiv\left(C_{i}^{P}+C_{i}^{D}\right)$. Finally, assume that a winning plaintiff never pays its own costs, while a losing plaintiff will pay a fraction $\lambda$ of the defendant's costs ${ }^{17}$ so that the total costs to the plaintiff loses a de novo case is given by $\mathrm{C}_{\mathrm{N}}^{\mathrm{P}}+\lambda \cdot \mathrm{C}_{\mathrm{N}}^{\mathrm{D}}=\mathrm{C}_{\mathrm{N}}-(1-\lambda) \cdot \mathrm{C}_{\mathrm{N}}^{\mathrm{D}}$.

If a case goes to court, two events are possible. The case is decided in favour of the plaintiff, in which case it receives damages, while the defendant pays damages and costs. The case is decided in favour of the defendant, in which case the plaintiff pays the share of costs determined by the cost allocation rules, while the defendant meets whatever costs are left unpaid by the plaintiff. The expected outcome of the court case provides the backdrop for negotiations to reach an out-of-court settlement. Because these settlements save legal costs, they are efficient and desirable. ${ }^{18}$

\subsection{The expected outcome of a de novo case}

The expected present discounted monetary value to the plaintiff of a de novo case can be written as:

$$
\mathrm{S}_{\mathrm{N}}^{\mathrm{P}}=\delta^{\mathrm{t}_{\mathrm{N}}} \cdot\left(\mathrm{p}_{\mathrm{N}} \cdot \mathrm{D}_{\mathrm{N}}-\left(1-\mathrm{p}_{\mathrm{N}}\right) \cdot\left(\mathrm{C}_{\mathrm{N}}-(1-\lambda) \cdot \mathrm{C}_{\mathrm{N}}^{\mathrm{D}}\right)\right)
$$

Note that with this expectation, the plaintiff in such a case would never settle for less than $S_{N}^{\mathrm{P}}$. The expected present discounted monetary value of the total cost of the case to the defendant is given by:

\footnotetext{
${ }^{16}$ Unlike Kauper and Snyder (1985), we assume that both plaintiff and defendant have the same assessment of the likelihood of plaintiff success. Differences in assessments can lead the two parties to go to court rather than to settle, which wastes resources and hence lead to worse outcomes for both parties. Kauper and Snyder show that difference can lead the plaintiff to prefer a follow-on case. For simplicity we assume that an infringement finding by the competition authority will result in an award to the plaintiff should the case come to court (ignoring other obstacles which might include causation, quantification, antitrust injury, standing and the availability of a passing-on defence). This is appropriate given that the principles governing such issues have not been given much consideration by the national and Community courts.

${ }^{17}$ This fits both the UK and the US. In the UK, generally the loser pays costs, $\lambda=1$. This is the norm for most, but not all, EU member states. In the US, exceptionally for private antitrust cases, the plaintiff does not pay her own costs if successful, while $\lambda=0$.
}

${ }^{18}$ Absent any strategic motives on the part of the plaintiff. 


$$
S_{N}^{D}=\delta^{t_{N}} \cdot\left(p_{N} \cdot\left(D_{N}+C_{N}\right)-\left(1-p_{N}\right) \cdot(1-\lambda) \cdot C_{N}^{D}\right)
$$

Note that the defendant will not settle for more than $S_{\mathrm{N}}^{\mathrm{D}}$. Assume that settlement can be achieved before any of the costs are incurred. Then the difference between the minimum for the plaintiff and the maximum for the defendant gives us the range for potential settlement, $\mathrm{S}_{\mathrm{N}}^{\mathrm{D}}-\mathrm{S}_{\mathrm{N}}^{\mathrm{P}}=\delta^{\mathrm{t}_{\mathrm{N}}} \cdot \mathrm{C}_{\mathrm{N}}$. There is a number of different ways in which this could be split, depending on the bargaining power of the two parties to the case. We will assume that the gains from settling is split evenly, but nothing rests on this. Thus the expected gain from a de novo case is

$$
\mathrm{S}_{\mathrm{N}}=\mathrm{S}_{\mathrm{N}}^{\mathrm{P}}+\frac{1}{2} \cdot \delta^{\mathrm{t}_{\mathrm{N}}} \cdot \mathrm{C}_{\mathrm{N}}=\delta^{\mathrm{t}_{\mathrm{N}}} \cdot\left(\mathrm{p}_{\mathrm{N}} \cdot \mathrm{D}_{\mathrm{N}}+\frac{1}{2} \cdot \mathrm{C}_{\mathrm{N}}-\left(1-\mathrm{p}_{\mathrm{N}}\right) \cdot\left(\mathrm{C}_{\mathrm{N}}-(1-\lambda) \cdot \mathrm{C}_{\mathrm{N}}^{\mathrm{D}}\right)\right)
$$

\subsection{The expected outcome of a follow-on case}

We will for simplicity assume that the plaintiff never starts a follow-on case unless the competition authority established a violation and hence will never lose a case. Moreover we would expect the costs of the plaintiff to be modest relative to the costs of a de novo case. Given this, the expected present discounted monetary value to the plaintiff of a follow-on case once the competition authority case has been decided can be written as:

$$
\mathrm{S}_{\mathrm{F}}^{\mathrm{P}}=\delta^{\mathrm{t}_{\mathrm{F}}^{\mathrm{FO}}} \cdot \mathrm{D}_{\mathrm{F}}
$$

The expected costs to the defendant is:

$$
S_{F}^{\mathrm{P}}=\delta^{\mathrm{t}_{\mathrm{F}}^{\mathrm{FO}}} \cdot\left(\mathrm{D}_{\mathrm{F}}+\mathrm{C}_{\mathrm{F}}\right)
$$

As in the de novo case, the gains from settling are the present discounted value of the costs saved, but in this case discounted back to the beginning of the follow-on case, $\delta^{\mathrm{F}_{\mathrm{F}}^{\mathrm{FO}}} \cdot \mathrm{C}_{\mathrm{F}}$. Thus the expected value of a follow-on case at the point of detecting the violation is:

$$
S_{F}=\delta^{t_{F}^{c a}} \cdot p_{F} \cdot\left(S_{F}^{P}+\frac{1}{2} \cdot \delta^{t_{F}^{F_{F}}} \cdot C_{F}\right)=\delta^{t_{F}} \cdot p_{F} \cdot\left(D_{F}+\frac{1}{2} \cdot C_{F}\right)
$$

Note in passing that the plaintiff has a strong incentive to talk up the cost of a follow-on case in order to get a bigger offer of a settlement. This adverse effect on the incentives to keep the costs of legal cases low is stronger than that found by Wagener (2003) for the one-way fee shifting system.

\subsection{Comparison and analysis}

Comparing the two expected gains, a de novo case will be preferred by the plaintiff is $\mathrm{S}_{\mathrm{N}}>\mathrm{S}_{\mathrm{F}}$. We can write this as 


$$
\delta^{t_{N}} \cdot\left(p_{N} \cdot D_{N}+\frac{1}{2} \cdot C_{N}-\left(1-p_{N}\right) \cdot\left(C_{N}-(1-\lambda) \cdot C_{N}^{D}\right)\right)>\delta^{t_{F}} \cdot p_{F} \cdot\left(D_{F}+\frac{1}{2} \cdot C_{F}\right)
$$

While the expression so far has allowed the cost allocation rule to be flexible enough to cover several jurisdictions, we will in the remainder focus on the most common form of cost allocation within the EU, where loser pays all, implying that $\lambda=1$. Rewriting equation (3) we can express this as:

$$
\delta^{t_{N}} \cdot p_{N} \cdot D_{N}-\delta^{t_{F}} \cdot p_{F} \cdot D_{F}>\frac{1}{2} \cdot\left(\delta^{t_{F}} \cdot p_{F} \cdot C_{F}-\delta^{t_{N}} \cdot p_{N} \cdot C_{N}\right)+\frac{1}{2} \cdot \delta^{t_{N}} \cdot\left(1-p_{N}\right) \cdot C_{N}
$$

Where the inequality in (4) holds, the expected value of a de novo case to a plaintiff is higher than the expected value of a follow-on case and hence the plaintiff faced with relevant information will prefer to initiate a de novo case rather than pass information on to the competition authority. ${ }^{19}$ To assess this likelihood, we will look at the left-hand-side and the right-hand-side of (4) separately. ${ }^{20}$ Note that the former relates to differences in expected damages while the latter relates to differences in expected costs. Secondly, if the left-handside is negative, any positive incentive to pursue a de novo case must come from the cost side and comparing (1) $)^{21}$ and (2) this implies that the probability of winning the de novo case is relatively high and the costs relatively low.

We would normally expect that the expected damages paid to the plaintiff is no lower in the follow-on case than the de novo case, $\mathrm{p}_{\mathrm{F}} \cdot \mathrm{D}_{\mathrm{F}} \geq \mathrm{p}_{\mathrm{N}} \cdot \mathrm{D}_{\mathrm{N}}$, mainly because once the potential violation has come to light, the probability of satisfying the required standard of proof for finding a violation is higher when the expertise and the resources of the competition authority are brought to bear on the problem. ${ }^{22}$ If this is true, the left-hand-side can only be positive if $\delta^{\mathrm{t}_{\mathrm{N}}}>\delta^{\mathrm{t}_{\mathrm{F}}}$, which in turn, as $0<\delta \leq 1$, imply that $\mathrm{t}_{\mathrm{N}}<\mathrm{t}_{\mathrm{F}}$, i.e. the de novo case must reach an outcome quicker.

\footnotetext{
${ }^{19}$ Note that we have assumed that the plaintiff is risk-neutral. If the plaintiff is risk averse, the balance swings in favour of follow-on cases because these are assumed risk-free.

${ }^{20}$ The value of a number of the parameters are determined jointly, something which the discussion in the paper does not reflect accurately. If may for example be that the same information boosts the probability of winning, the damages awarded and shortens the length of the case. However, in this case, our conclusions are strengthened.

${ }^{21}$ Note that for $\lambda=1$, (1) can be written as $S_{N}=\delta^{t_{N}} \cdot\left(p_{N} \cdot D_{N}+\frac{1}{2} \cdot C_{N}-\left(1-p_{N}\right) \cdot C_{N}\right)$

${ }^{22}$ The one thing which goes against this assumption is that the standard of proof in de novo cases is likely the civil "on the balance of probabilities". Although it is still unclear exactly what standard of proof the competition authorities in the UK will be held to, it appears from JJB Sports plc v OFT [2004] CAT 17, [2005] CompAR 29 (para 204: "strong and compelling" evidence) to be higher than the civil standard. Note that a follow-on case would be locked into this higher standard of proof unless a follow-on action could be pursued where the competition authority did not find a violation. This has the potential to create an inconsistency in what has to be proven. The exact effect is at present unclear and is the subject for further research.
} 
The right-hand-side is harder to sign. On the cost side, although the plaintiff has an incentive to talk up the costs of a follow-on case, we would expect that the costs in the de novo case is much higher, $\mathrm{C}_{\mathrm{N}}>\mathrm{C}_{\mathrm{F}}$, because the plaintiff is unable to free ride on the resources of the competition authority. It would be natural to expect the first term on the right-hand-side to be negative, and as the second term is positive, the overall sign is ambiguous. If the costs, the probabilities and times to a decision were all the same for both cases, the right-hand-side would reduce to $\frac{1}{2} \cdot \delta^{t} \cdot(1-p) \cdot C$, which is clearly positive. If the cost of the follow-on case was zero, the right-hand-side would reduce to $\frac{1}{2} \cdot \delta^{t_{N}} \cdot\left(1-2 p_{N}\right) \cdot C_{N}$ which is positive so long as $p_{N}<\frac{1}{2}$. This suggests that the key is the probability that the plaintiff wins a de novo case. If this probability is high, then the righthand-side is negative and hence the inequality in (4) might hold even in cases where the lefthand-side is also negative (if less so). The reason for this is that the high probability of success reduces the potential costs of the plaintiff in a de novo case while the higher expected court costs in such a case imply a more generous offer of a settlement.

It is constructive to consider an alternative way to express (4) given below.

$$
\delta^{t_{N}} \cdot p_{N} \cdot\left(D_{N}-\frac{1}{2} \cdot C_{N}\right)-\delta^{t_{F}} \cdot p_{F} \cdot\left(D_{F}-\frac{1}{2} \cdot C_{F}\right)>\frac{1}{2} \cdot \delta^{t_{N}} \cdot\left(1-p_{N}\right) \cdot C_{N}
$$

Note that $D_{i}-\frac{1}{2} \cdot C_{i}$ is a measure of the net value of a case in which the costs are split. We would expect these to be greater for follow on cases where the probability of winning is also likely to be greater. This further points to the importance of speed. Secondly looking at the new right-hand-side, this shows the importance of the costs of the de novo case being modest as well as the chance of the plaintiff winning being high.

\subsection{Summary}

Summing up, the model demonstrates that the key to getting more de novo cases is that these cases must reach a conclusion much quicker than follow-on cases. The intuition is fairly obvious. Success in a follow-on case is a relative certainty for a plaintiff, while a de novo case involves a greater risk of losing. Thus unless follow-on cases involve costly waiting, they will be favoured. The only ways this could be overturned is if private courts are more generous in awarding damages in de novo cases or, having a similar effect, the probability of proving an infringement is greater before a court as compared with the competition authority (as may be the case where the court applies a lower standard of proof than does the competition authority). In addition to this, de novo cases are more likely the higher is the probability of winning such a case, i.e. the stronger the evidence the plaintiff 
possesses and the simpler the case is to put to the courts. The intuition is that this reduces the risk of a decision adverse to the plaintiff in the de novo case. Lower costs of de novo case have two opposite effects. They lead to a smaller payout for the plaintiff where it loses but they also lead to less generous settlements. Finally, where de novo cases are quicker, the size of the discount factor matters. In jurisdictions where no or only limited interest payments are added to damages, there are stronger incentives for de novo as compared with follow-on cases where the former are relatively quicker.

\section{$4 \quad$ Policy}

With this little model to hand, what can we say about how to encourage de novo cases? We will focus the discussion on the areas of collusion, predation and restrictive practices such as foreclosure.

For collusion, direct buyers - the plaintiffs with relevant information and incentives to oppose the practice - may have access to incriminating evidence, but where this is insufficient, they have a lesser prospect of revealing information than the competition authority: even in those jurisdictions like the UK with the most generous discovery rules, the competition authority is always in a superior position from an information gathering point of view. Moreover, plaintiffs do not have access to a powerful leniency policy instrument. ${ }^{23}$ Thus it is likely not only that it would be considerably more costly for the private plaintiff to establish an infringement but also that the probability of such a finding would be lower. Without confessions, such cases are likely to be protracted (although this is also the case for public cases against cartels). Finally, there is no evidence that private courts would take into consideration that the cartel members had already been fined. The converse may be true, however. In the US, the sentencing guidelines for the Department of Justice Antitrust Division in cartel cases state clearly that they must in their fining policy take into consideration the ability of the defendants to meet their civil liabilities arising from the case. ${ }^{24}$ Thus there seems very little advantage in terms of the variables $t, p$ and $D$, while there are substantial disadvantages in terms of costs. Without a large carrot such as multiple damages, it is hard to see how such offences would attract de novo cases.

\footnotetext{
${ }^{23}$ They could in theory offer one of the cartel members to settle for a minimal amount in return for incriminating evidence about the other cartel members. The legality of such an approach is far from clear. For a discussion of joint and successive actions, see Deakin et al. (2003, p. 850-865)

${ }^{24}$ United States Sentencing Commission Guidelines, U.S.C. §3612(f)(3)(A) and $\S 8 C 3.3$.
} 
For predation, the plaintiff is likely a rival and, where used non-strategically, time will be of the essence since if the predation is not brought to an end the plaintiff may well go out of business. Such cases are good candidates for de novo cases. However, the plaintiff will need to be in possession of information over the cost structure of its competitor in order to satisfy the cost floor rules for predation. It is arguable that, even without precise cost information, a competitor will be in a better position than a competition authority to adduce evidence of predatory pricing given its location in the market in question. Where prices exceed the lower floor (normally average variable costs) but not the upper floor (average total costs) the plaintiff may also need to show that there was an exclusionary intent on the part of the defendant which is arguably as difficult as obtaining confessional evidence in a cartel case. The revelation of information facilitated by litigation also comes with certain dangers. As many have pointed out, see in particular Crane (2005), firms have an incentive to misuse private litigation as an opportunity to price signal. Thus while we might get such cases it is necessary to have adequate safeguards in place to deter strategic litigation.

For restricted practices, the plaintiff is prevented by an agreement with the defendant from doing what it wants to, for example, by an exclusive purchasing obligation. Such cases may well be costly to pursue because the issues of whether the practice is illegal and how much the plaintiff has been harmed are complex. In many cases, therefore, the outcome will be uncertain, but the competition authority has no obvious advantage in informational terms. It may have more expertise, but many of these cases are closely related to contract cases and hence courts have more experience than is normally the case in competition litigation. The deciding factor here is likely to be whether it is quicker to pursue a de novo case and possibly even whether it would be even quicker to pursue the matter as a contract case. ${ }^{25}$ However, if these cases are such that we cannot distinguish between private suits aimed at opportunistic contract modification and those aimed at alleviating damaging restraints of trade, private enforcement may still end up doing more harm than good. Again, it is necessary to have in place safeguards to deter strategic litigation.

\section{Conclusions}

In this paper we have looked at the conditions necessary to encourage plaintiffs with the relevant private information about violations of competition law to opt for de novo rather

\footnotetext{
${ }^{25}$ Salop and White (1986, p. 1048-49) investigate this for the US Georgetown Study sample and find that contract like cases are not resolved quicker. But here triple damages skews the analysis, since plaintiffs may be willing to wait for the triple damages rather than getting an even quicker resolution to its predicament.
} 
than follow-on cases. Where plaintiffs have in their possession the necessary information, or where this information can be readily obtained through efficient discovery rules, de novo cases add more to overall enforcement than do follow-on cases. The latter represent little more than free-riding on public resources.

To encourage this beneficial form of private enforcement which increases the overall level of enforcement we need to ensure that the costs of these cases are as low as possible and decisions are reached as quickly as possible and certainly far quicker than is the case for follow-on actions. This also has implications for the sort of cases which are likely to be pursued, with the most likely being those where the future of the plaintiff is threatened, such as predation cases or vertical restraints cases. In such instances the possible benefits of bringing a case (by either route) goes beyond the award of damages; it extends to gains from securing that the anticompetitive practice ceases. For the purposes of the model advanced in this paper, we can capture this through an increase in the impatience of the plaintiff. This could either be through a lowering of the per period discout factor, or even through the discount factor being zero after a point in time. A reduction in the discount factor ensures that the value of a quick resolution is increased. In any case, more speedy resolution of cases, including appropriate incentives to settle, brings with it wider benefits to society.

Given the need to encourage efficient forms of litigation, incentives to settle should be maintained. Such incentives should, however, not run counter to the bringing of de novo cases in favour of follow-on cases. Kauper and Snyder (1985) were concerned with the incentives for firms to settle their case and with what makes settlement more likely. In their model, cases do not settle when the two parties differ too much in their assessment of the probability that the plaintiff will succeed. ${ }^{26}$ Because it is possible that both parties to a $d e$ novo case are too optimistic about their own chance of success, they may fail to settle and this lowers the expected returns to the plaintiff of initiating such a case. The outcome in a follow-

\footnotetext{
${ }^{26}$ With complete information all cases should settle. The law and economics literature on tort identify two broad classes of models in which settlement may not happen. One class, to which the Kauper and Snyder (1985) model belongs, assume differences in assessments and is often referred to as the "differing perception" model since both parties are reluctant to settle as the overestimate the quality of their own case. The other class, often referred to as the "asymmetric information" model, assume asymmetry of beliefs so that the plaintiff is better informed about the strength of its case. To settle all possible cases, the defendant has to make the plaintiff with the best possible case accept the offer. This means that in most cases the defendant is paying too much and it is better to lower the offer and accept that there is a chance of a rejection and a subsequent court case. For a survey of these models, see Miceli (1997, ch. 8). For a survey of the economic approach to litigation, see Cooter and Rubinfeldt (1989)
} 
on case is much more of a foregone conclusion, ${ }^{27}$ and settlement should happen for sure in those cases. Their conclusion is that because of the much reduced risk of the case going to court rather than being settled, plaintiffs may prefer to wait and initiate a follow-on case. ${ }^{28}$ This result is important because it provides yet another reason for a bias towards follow-on cases. Given this systemic bias in favour of follow-on cases, there may be good reasons to strengthen the incentives of a plaintiff to pursue de novo cases instead. One way would be to recover some of the costs of the competition authority in a follow-on case. This would be justified given the free-rider problem that we have referred to throughout this paper. On the other hand, this rule would have little or no effect if the cost rule would result in this cost being recovered from the defendant rather than the plaintiff.

The model in section three made a number of simplifying assumptions which deserve some mention. Unlike Kauper and Snyder (1985) we assume that the two parties agreed on the probability of the plaintiff winning the court case. Relaxing this assumption would as argued above make the follow-on case more attractive to the plaintiff since it would settle for sure and hence, at least on average, save legal costs. Secondly, we assumed that the plaintiff was risk-neutral. As such it only cared about the average outcome, not about how risky each individual case is. As plaintiffs in competition cases typically are much smaller firms than the defendant (Salop and White (1988)), one might think it reasonable to assume that they are averse to risk. ${ }^{29}$ If the plaintiff is risk averse, again the follow-on case is much more attractive as it is (much more of) a sure thing.

The availability of treble damages in the US gives strong incentives for firms to pursue private actions. Analysing the empirical analysis of data the Georgetown study, Kauper and Snyder (1985) find that for the 1973-1983 period, follow-on cases in the US represented less than $20 \%$ of private cases. This result is misleading, however, for two reasons. First, follow-on cases involved significantly larger amounts of money, partly because of an over representation of price-fixing cases. Secondly, many of the cases in the Georgetown Study appeared to be contract cases rather than antitrust cases, the triple damages rule itself distorting the incentives to pursue the antitrust rather than the contract

\footnotetext{
${ }^{27}$ The problem of establishing causation as well as the size of damages should not be underestimated, but there is much greater scope to disagree on whether a court or competition authority would find a violation.

${ }^{28}$ We will count credible threats of pursuing a case as an initiation. Note that unlike the US, cases un the UK and EU which are settled leave very little evidence of their existence.

${ }^{29}$ That is, faced with two possible lotteries, such as a court case or a settlement, each having the same expected returns, they would prefer the one with less variability.
} 
route. Of course, such cases can only be pursued de novo. Those problems aside, the adoption of a treble-damages rule (or other such device) in de novo cases only could be used to give incentives to plaintiffs to pursue de novo instead of follow-on actions. This is appropriate given that the asymmetries which exists between the two alternative routes.

We noted at the beginning the need to view the enforcement regimes - public and private - as part of a unified system. In that context we observed that increased private enforcement may alter the behaviour of the competition authority, for example, by its applying a higher level of scrutiny to the evidence of complainants. The prospect of an increased use of private enforcement may also influence the competition authority in the manner in which it selects the cases it wishes to take forward. For example, where a complainant reveals to the authority information sufficient for the complainant itself to secure an infringement finding (or where such information would be readily available under discovery rules) the authority may well wish to forebear from intervening.

The overriding message of this paper is the complexity of designing an appropriate private litigation regime which on the one hand promotes those cases which increase welfare in society but at the same time limits any adverse effects from strategic behaviour. ${ }^{30} \mathrm{An}$ appropriate design will include checks and balances and must recognise that marginal changes to design may have either no or alternatively very large effects. Just one missing piece of the puzzle may mean that the private enforcement does not work at all. Finding that last piece, however may lead to a significant jump in use.

\footnotetext{
${ }^{30}$ On the potential for strategic action by plaintiffs see Harker and Hviid (2006) and the papers cited therein.
} 


\section{References}

Brenner, S. 2005, “An Empirical Study of the European Corporate leniency Program.” Paper presented at the 2005 EARIE conference, Porto.

Cooter, R. and D. Rubinfeldt, 1989, "Economic Analysis of Legal Disputes and Their Resolution", Journal of Economic Literature 20, 1067-

Crane, D.A., 2005, “The Paradox of Predatory Pricing”, Cornell Law Review 91:1, 1-66.

Deakin, S., A. Johnston and B. Markesinis, 2003, Markesinis and Deakin's Tort Law $5^{\text {th }}$ Edition, Oxford University Press.

Harker M. and M. Hviid, 2006, "The Incentive Effects of Private Enforcement", draft Centre for Competition Policy, UEA.

Kauper, T.E. and E.A. Snyder, 1985, "An Inquiry into the Efficiency of Private antitrust Enforcement: Follow-on and Independently Initiated Cases Compared", Georgetown Law Journal 74, 1163-1230

Rodger, B.J. and A. MacCulloch, 1998, "Community Competition Law Enforcement, Deregulation and Re-regulation: The Commission, National Authorities and Private Enforcement", The Columbia Journal of European Law 4, 579-612.

Miceli, T.J., 1997, Economic of the Law, Oxford University Press.

Salop, S.C. and L.J. White, 1986, "Economic Analysis of Private Antitrust Litigation", Georgetown Law review 74, 1001-1064.

Salop, S.C. and L.J. White, 1988, "Prviate Antitrust Litigation: Introduction and Framework" in White (ed.), Private Antitrust Litigation: New Evidence, New Learning, MIT Press: Cambridge Mass.

Stephenson, M.C., 2005, "Public Regulation of Private enforcement: ..."Virginia Law Review 91, 94-173.

Wagener, W.H., 2003, "Modeling the Effect of One-Way Fee Shifting on Discovery Abuse in Private Antitrust Litigation", New York University Law Review 78, 1887-1928. 